\title{
Euclides de Medeiros Guimarães Roxo: o que tratam as Teses e Dissertações em História da Educação Matemática
}

\author{
Euclides de Medeiros Guimarães Roxo: what the Theses \\ and Dissertations in the History of Mathematical Education \\ deal with
}

\section{Euclides de Medeiros Guimarães Roxo: de qué tratan las Tesis y Disertaciones en Historia de la Educación Matemática}

\author{
Iran Abreu Mendes \\ Universidade Federal do Pará \\ Belém, Pará, Brasil \\ E-mail: iamendes1@gmail.com \\ Orcid: 0000-0001-7910-1602
}

\author{
Ana Paula Nascimento Pegado Couto Nascimento Couto \\ Universidade do Estado do Rio de Janeiro, Campus Maracanã \\ Belém, Pará, Brasil \\ E-mail: ana.couto16@hotmail.com \\ Orcid: 0000-0003-0586-2753
}

\begin{abstract}
Resumo: Este artigo é resultante de um estudo que teve como fonte de pesquisa as produções de teses e dissertações, defendidas no Brasil no período de 1990 a 2018, que tiveram a trajetória de professores de matemática como objetos de suas investigações. Nesse sentido, estabelecemos como objetivo delinear os modos como essas produções abordam a trajetória do professor Euclides Roxo, considerando suas ações docentes e produções acadêmicas. Para tanto foi realizado um levantamento e uma leitura dessas produções a fim de operacionalizar uma catalogação desses trabalhos em categorias que possibilitaram uma análise dos conteúdos produzidos e a identificação de abordagens estabelecida para tratar do tema. A análise foi realizada com base nos estudos de Hofstetter, Schneuwly e Freymond (2017). Os resultados apontaram que ao tratar da Trajetória de Euclides Roxo, os autores das produções apesar de ter o mesmo objeto em suas investigações abordaram de diferentes aspectos da Trajetória do professor Euclides Roxo.
\end{abstract}


Abstract: This article is the result of a study that I used as a research source for the production of thesis and dissertations, defended in Brazil from 1990 to 2018, that I also used as a guide for mathematics teachers as objects of their investigations. In this sense, we plant ourselves as an objective to profile the ways in which these productions approach the teacher of Euclides Roxo, considering their teaching actions and academic productions. For him, a relevance and teaching of these productions was carried out in order to make operational the cataloging of these works in categories that would allow an analysis of the contents produced and the identification of the established approaches to approach the thematic. The analysis was carried out based on studies by Hofstetter, Schneuwly and Freymond (2017). The results showed that while addressing the Euclid Roxo trayectoria, the authors of the productions, despite having the same object in their investigations, addressed different aspects of the Euclides Roxo teacher sector.

Keywords: History of Mathematical Education. Teachers' Trajectory. Euclides Roxo.

Resumen: Este artículo es el resultado de un estudio que tuvo como fuente de investigación la producción de tesis y disertaciones, defendidas en Brasil de 1990 a 2018, que tuvo como objetos de sus investigaciones la trayectoria de profesores de matemáticas. En este sentido, nos planteamos como objetivo perfilar las formas en que estas producciones abordan la trayectoria del profesor Euclides Roxo, considerando sus acciones docentes y producciones académicas. Para ello, se realizó una colecta y lectura de estas producciones con el fin de operativizar la clasificación de estas obras en categorías que permitieran un análisis de los contenidos producidos y la identificación de los enfoques establecidos para abordar la temática. El análisis se realizó en base a los estudios de Hofstetter, Schneuwly y Freymond (2017). Los resultados mostraron que al abordar la trayectoria de Euclides Roxo, los autores de las producciones, a pesar de tener el mismo objeto en sus investigaciones, abordaron diferentes aspectos de la trayectoria de éste profesor.

Palabras- chave: Historia de la Educación Matemática. Trayectoria de los profesores. Euclides Roxo.

Recebido em

$25 / 01 / 2021$

Aceito em

$2103 / 2021$ 


\section{INTRODUÇÃO}

A importância de se tomar as produções de teses e dissertações para estudos como objeto de investigação vêm se tornando cada vez mais frequentes nos últimos anos, ampliando um campo teórico-metodológico denominado na pesquisa1. Nesse tipo de estudos há dois projetos que vem se destacando pela realização de levantamento, classificação e análise das produções de dissertações e teses sobre História da Matemática no Brasil. Em nosso estudo fizemos um recorte dessa temática e tomamos como fonte de pesquisa as produções brasileiras das últimas três décadas (1990 a 2018), que apresentam informações acerca da Trajetória de professores de matemática brasileiros. Neste artigo trataremos de apensas um desses casos: a trajetória do professor Euclides de Medeiros Guimarães Roxo.

Entretanto, esclarecemos que antes de selecionar o personagem a ser focado nesse artigo, primeiramente realizamos um levantamento das pesquisas que tratam dessa temática no Centro Brasileiro de Referência em Pesquisa sobre História da Matemática - CREPHIMat ${ }^{2}$, sendo este um dos resultados do projeto de pesquisa mencionado. Nesse levantamento, identificamos 51 produções, das quais foram 19 Teses e 32 Dissertações (23 de Mestrado Acadêmico e 9 de Mestrado Profissional).

A partir dessa seleção, verificamos que mais de uma produção abordava o mesmo professor. Assim sendo, decidimos organizar as produções em grupos por professores. Após essa organização, e com base em uma pré-análise, nos chamou a atenção a quantidade de trabalhos que abordava cada professor. Percebemos que três professores ${ }^{3}$ se destacavam nesse quantitativo, e dentre esses optamos em focalizar nesse artigo o professor Euclides de Medeiros Guimarães Roxo por ser o mais abordado nas pesquisas com um total de 5 produções.

Com base nesse recorte fizemos uma leitura dessas cinco produções-a à luz do conceito de Expert em Educação, com intuito de interpretar o modo como essas

\footnotetext{
${ }^{1}$ Baseado nos estudos de Gamboa (2012).

${ }^{2}$ http://crephimat.com/

3 Dentre os quais estão: Euclides de Medeiros Guimarães Roxo com 5 trabalhos, Júlio César de Mello e Souza (Malba Tahan) com 4 trabalhos e Joaquim Gomes de Sousa (Souzinha) com 3 trabalhos.
} 


\section{Universidade Federal da Grande Dourados}

produções tratam a trajetória de vida e obra do professor Euclides Roxo, tendo em vista responder a seguinte questão: como as pesquisas de Mestrado e Doutorado em História da Educação Matemática, defendidas no Brasil entre 1990 e 2018, focalizam as trajetórias de ações docentes e produções acadêmicas do Professores Euclides de Medeiros Guimarães Roxo?

Assim, com o intuito de responder à questão lançada anteriormente, realizados um estudo com o objetivo de analisar os aspectos concernentes à trajetória do professor Euclides Roxo, tratados nas pesquisas de Mestrado e Doutorado que o focalizam, considerando suas ações docentes e produções acadêmicas. Nesse sentido, realizamos uma descrição analítica dessas produções a fim de operacionalizar uma catalogação desses trabalhos em categorias que possibilitassem uma análise dos conteúdos ${ }^{4}$ produzidos e a identificação das abordagens estabelecidas para tratar do tema, assim como, evidenciar elementos para outras pesquisas que pretendem tratar sobre os Experts em Educação.

Para detalhar o processo de pesquisa e elaboração da escrita deste artigo, apresentaremos a seguir o referencial teórico-metodológico adotado, no qual indicamos os princípios epistemológicos da pesquisa, a descrição analítica das produções que abordaram o professor Euclides Roxo, uma síntese dos modos de abordagens das produções e suas contribuições para as pesquisas sobre Expert em Educação, e um quadro-síntese das ações docentes e produções acadêmicas, e por fim as considerações finais sobre o estudo realizado.

\section{A EXPERTISE E O EXPERT EM EdUCAÇÃO}

Os estudos de Hofstetter, Schneuwly e Freymond (2017), no capítulo intitulado "Penetrar na verdade da escola para ter elementos concretos de sua avaliação" - A irreversível institucionalização do Expert em Educação (século XIX e XX) aborda o processo de constituição e institucionalização da Expertise do especialista em

${ }^{4}$ (Bardin, 2016) 
educação, por eles nomeado de Expert. Para esses autores entende-se como Expertise:

[...] uma instância, em princípio reconhecida como legítima, atribuída a um ou vários especialistas - supostamente distinguidos pelos seus conhecimentos, atitudes, experiências -, a fim de examinar uma situação, de avaliar um fenômeno, de constatar fatos. Esta expertise é solicitada pelas autoridades do ensino tendo em vista a necessidade de tomar uma decisão. (Hofstetter et al., 2017, p. 57)

A institucionalização da Expertise, do especialista em educação é um fenômeno concomitante à entrada do estado encarregado da instrução pública e à emergência do campo disciplinar "ciências da educação" (Hofstetter et al., 2017, p. 56), razão pela qual solicitam a Expertise tendo em vista a necessidade de uma tomada de decisão sobre o objeto investigado, a escola. Neste sentido, a solicitação da Expertise participa decisivamente da produção de novos saberes no campo pedagógico. A Expertise é, portanto, realizada por pessoas do meio escolar, isto é, pela profissão docente. Eles (os especialistas) são Experts pelo fato de que conhecem perfeitamente o ofício docente e nele se destacam (Hofstetter et al., 2017, p. 67).

De acordo com os estudos defendidos por Hofstetter et al. (2017), a constituição de um Expert atende a dois requisitos básicos. O primeiro diz respeito à necessidade desse profissional se destacar em seu ofício, pelos saberes que lhe são próprios para a condução de seu trabalho, como por exemplo, os saberes científicos e os saberes da experiência. O segundo requisito é que além de necessitar ter a posse desses saberes, este profissional deverá ocupar um cargo, posto, cadeira etc. e a ele é permitido, por meio desse posto, sistematizar saberes específicos para o funcionamento escolar, tais como a elaboração de programas para o ensino, cursos para os professores, além de outras atividades que estejam ligadas à sua Expertise.

Assim, pelos estudos percebe-se que o conceito de Expert se refere, não somente, no sentido usual do dicionário de ser especialista em uma área específica, mas também ocupar algum cargo o qual por meio desse cargo possibilite a sistematização de saberes no âmbito escolar como aborda os estudos de Hofstetter 


\section{Universidade Federal da Grande Dourados}

et al. (2017). Portanto, para esta pesquisa foi utilizado o conceito de Expert em Educação à luz dessas perspectivas.

De acordo com o Projeto Temático ${ }^{5}$ ao qual esse estudo foi vinculado, um dos caminhos para tratar o Conceito de Expert nos projetos de pesquisa é: 1) Identificar uma convocatória/mandato; 2) Analisar a demanda efetuada pela autoridade educacional; 3) Seguir as ações dos experts; 4) Situar as referências produzidas relativamente ao já existente; 4) Identificar as novas produções; 5) Elaborar uma narrativa explicativa para as mudanças e surgimentos de novos saberes (Valente, 2018, p. 06).

Ao tentar içar um sujeito a Expert deve-se levar em consideração, além de sua trajetória docente, os novos saberes produzidos por ele. Esses saberes de acordo com o projeto Temático são os saberes profissionais do professor que ensina matemática. Tais saberes "referem-se a expressão aos saberes de formação de professores dado pela articulação entre os saberes a ensinar e os saberes para ensinar. Os primeiros como aqueles saberes que constituem o objeto de trabalho da docência; e os saberes para ensinar, referem-se às ferramentas do ofício de ser professor" (Valente, 2018, p. 09).

Assim, com as nossas palavras, os Saberes profissionais docentes é tudo que o professor precisa saber para ensinar, que engloba os dois saberes: "a" e "para" ensinar. Ainda, de acordo com Hofstetter, Schneuwly (2017, p. 131), os saberes a ensinar, refere-se a "saberes que são objetos do seu trabalho do professor", e os saberes para ensinar, refere-se a "saberes que são ferramentas dos seus trabalhos". O professor deverá mobilizar esses dois saberes que não se separa um do outro.

No caso dessa pesquisa, não temos o intuito de içar o Professor Euclides Roxo abordado nas produções em análise à condição de expert, mas sim identificar nessas produções os modos de abordagens e as ações/ocupações do professor a partir da trajetória apresentada nas produções, com intuito de inventariar elementos que

5 OS EXPERTS E A SISTEMATIZAÇÃO DA MATEMÁTICA: para a formação de professores dos primeiros anos escolares, 1890-1990 


\section{Universidade Federal da Grande Dourados}

possam contribuir para outras pesquisas que tenham interesse em analisar os professores que podem ser tidos, ou não, como Expert em Educação.

\section{EUCLIDES DE MEDEIROS GUIMARÃES RoXO: NAS TESES E DISSERTAÇÕES}

Conforme mencionado no início desse artigo, na realização do levantamento das produções identificamos 5 trabalhos que apresentam informações relacionadas à trajetória do professor Euclides de Medeiros Guimarães Roxo (uma Tese e quatro dissertações). A partir desse levantamento, realizamos uma Descrição analítica ${ }^{6}$ das produções com intuito de compreender de que modo os autores abordam o Professor Euclides Roxo em seus trabalhos. Neste sentido, a análise foi realizada de forma cronológica, respeitando o ano de defesa das produções.

Assim, iniciamos com a dissertação de Aparecida Rodrigues Silva Duarte intitulada Henri Poincaré e Euclides Roxo: subsídios para a história das relações entre Filosofia da Matemática e Educação Matemática, defendida em 2002. No trabalho a autora estudou as relações entre Filosofia da Matemática e Educação Matemática, focando especificamente as influências exercidas pela corrente intuicionista, representada pelo filósofo matemático francês Henri Poincaré, nas propostas pedagógicas defendidas pelo professor de Matemática Euclides Roxo, durante o período histórico compreendido entre 1927 e 1940.

Neste sentido, a pesquisadora analisou, cronologicamente, os textos publicados por Euclides Roxo durante este período, verificando como este se apropriou das ideias filosóficas de Henri Poincaré. Entre essas publicações estão: Livros didáticos, artigos publicados em jornais e revistas, o programa oficial de ensino de Matemática de 1931, e capítulo de livros especificamente pedagógicos.

Ao tratar dessas publicações a autora inicialmente descreve os documentos e depois analisa comparativamente as ideias de Henri Poincaré e as publicações do

${ }^{6}$ Bardin (2016) 
Professor Euclides Roxo visando identificar nos conteúdos e investigados, pontos de convergência entre os pensamentos de Poincaré e Euclides Roxo.

Ao abordar o Professor Euclides Roxo em seu trabalho, a autora inicialmente organizou uma biografia que contém dados relativos ao período de vida, formação acadêmica, atuação profissional e produções do referido professor. Nesta biografia verificamos que a maior parte da trajetória de Roxo foi no Colégio Pedro II, passando de aluno a professor substituto de Aritmética, em seguida assume a Cátedra e posteriormente Direção do Externato e por fim Diretor do Internato do Colégio Pedro II.

A partir da leitura e análise da Dissertação verificamos que em seu trabalho a autora abordou o Professor Euclides de Medeiros Guimarães Roxo pelo viés de suas produções, para compreender como ocorreu a apropriação das ideias de Henri Poincaré pelo professor brasileiro. O diferencial em seu trabalho é justamente em saber quais teriam sido as influências sofridas por Euclides Roxo para a proposição da completa modernização da Educação Matemática no Brasil.

Ao comparar as ideias de Euclides Roxo com as de Henri Poincaré com base em suas produções, podemos enfatizar esse aspecto com um dos pontos de abordagem descritivo-analítica em pesquisas que podem "situar as referências produzidas relativamente ao já existente" (Valente, 2018, p. 6). Assim, no trabalho da Aparecida Duarte observamos uma abordagem centrada nas produções intelectuais de Euclides Roxo, mais especificamente centrada na análise do conteúdo dessas produções.

O segundo trabalho analisado foi a Dissertação de Arlete Werneck intitulada Euclides roxo e a reforma Francisco Campos: a gênese do primeiro programa de ensino de Matemática brasileiro, defendida em 2003, que trata do estudo do Programa de Ensino de Matemática, do Decreto número 19.890 de 18 de abril de 1931, que dispõe sobre a organização do ensino secundário brasileiro. Este ato legislativo em conjunto com outros, ficou conhecido como Reforma Francisco Campos.

O trabalho de Arlete Werneck, assim como o trabalho da Aparecida Duarte, é parte integrante do Projeto História da Educação Matemática no Brasil, 1920-1960, coordenado pelo Prof. Dr. Wagner Rodrigues Valente. A Dissertação de Werneck, 
diferenciando do trabalho de Duarte (2002), buscou contribuir especificamente com a pesquisa da gênese do programa de Matemática da Reforma Francisco Campos. Esse programa organizou, em nível nacional, pela primeira vez, a disciplina escolar Matemática, tendo como responsável direto da elaboração o professor Euclides Roxo.

Na seção intitulada Sobre Euclides de Medeiros Guimarães Roxo, contida no capítulo III, a autora discorre sobre trechos da vida de Euclides e sua influência na modernização da reforma de ensino. Ao focar Euclides Roxo em seu trabalho, Werneck (2003) não apresenta uma biografia do professor, e sim fatos/episódios específicos no decorrer de sua vida acadêmica e profissional.

Quanto a sua vida acadêmica, de acordo com Werneck (2003), Euclides Roxo foi estudante do internato Pedro II, o qual saiu como bacharel em 1909, depois de um curso brilhante, e em 1916, formou-se em Engenheiro Civil na Escola Politécnica do Rio de Janeiro. A sua trajetória de professor e diretor no colégio Pedro II, além de algumas ocupações como membro do Conselho Nacional de Ensino, membro do Conselho Diretor da Associação Brasileira de Educação, e presidente da sessão de Ensino Secundário da mesma Associação.

Em suas considerações finais, Werneck (2003) concluiu que Euclides Roxo, ao invés de programas, utilizou-se de livros de vários autores, de diferentes países, para a elaboração do primeiro programa brasileiro de Matemática, ou seja, apropriou-se, portanto, do movimento internacional da Matemática $^{7}$, assim como, dos livros mencionados no prefácio de seu livro Curso de Mathematica Elementar, resultando desse processo, o primeiro programa de ensino da Matemática no Brasil. A autora ainda ressalta que apesar do livro não ter uma correspondência totalmente sequenciada com o programa, a análise levou a concluir que um foi feito para o outro.

A partir da leitura e análise da Dissertação de Arlete Werneck, verificamos que, em seu trabalho, a autora abordou o Professor Euclides Roxo pelo viés do Programa de Ensino de Matemática de 1931, o qual o mesmo foi responsável direto pela

\footnotetext{
${ }^{7}$ O Movimento da Matemática Moderna foi um movimento internacional do ensino de matemática que surgiu na década de 1960 e se baseava na formalidade e no rigor dos fundamentos da teoria dos conjuntos e da álgebra para o ensino e a aprendizagem de Matemática (Werneck, 2003)
} 
elaboração, buscando, assim, compreender como ocorreu a gênese das ideias desse programa. Foi possível identificar que a autora apesar de identificar que o Programa de Matemática de 1931 foi produzido concomitante ao livro Curso de Mathematica Elementar, ambos foram compilações de vários livros, compondo uma obra totalmente diferente das demais obras existentes.

As conclusões de Werneck (2003) nos levaram a fazer relações com o referencial teórico adotado para nossa pesquisa, especificamente para o conceito de Expert em Educação, o qual leva em consideração a "produção de novos saberes por um personagem". Isso nos leva a refletir se de fato Euclides Roxo produziu novos saberes tanto nos seus livros como no Programa de 1931, já que tanto o livro como o programa foram uma compilação de ideias de vários autores. Dentre esses, já sabemos pelo trabalho de Duarte (2002), anteriormente analisado, que tanto Henri Poincaré como Felix Klein influenciaram nas obras de Euclides Roxo.

No trabalho de Arlete Werneck, observamos uma abordagem centrada nas produções intelectuais de Euclides Roxo, do Programa de Ensino de 1931. Assim, o trabalho de Arlete Werneck não se centrou no Professor Euclides Roxo, pois a pesquisadora optou por focar a atenção na busca das origens do programa de Matemática produzido pelo professor.

Por mais que o trabalho de Werneck (2003) não apresente um capítulo exclusivo para Euclides Roxo, pois esse não era o seu objeto de estudo principal, decidimos por manter esse trabalho nas análises, uma vez que o mesmo contribuiu para esclarecer e complementar algumas informações para o papel de Euclides Roxo como participante na criação do primeiro programa de ensino da disciplina Matemática no Brasil. Além disso, a abordagem utilizada pela pesquisadora ao focar o professor Euclides Roxo, em seu trabalho, aumentou o leque de abordagens utilizadas para interpretar a trajetória de vida e obra de professores que inscreveram suas marcas na história do desenvolvimento da educação matemática brasileira.

O terceiro trabalho em análise é a Tese de Bruno Alves Dassie intitulada Euclides Roxo e a constituição da Educação Matemática no Brasil, defendida em 2008. O qual buscou analisar como a atuação de Euclides Roxo e suas propostas para o ensino da 


\section{Universidade Federal da Grande Dourados}

matemática escolar em nível secundário, no período compreendido entre as décadas de 1920 e 1940, contribuíram para a constituição da Educação Matemática no Brasil.

Para isso, o autor organizou o seu estudo em duas partes. A primeira parte teve como intuito apresentar a trajetória de vida de Euclides Roxo, desde a sua entrada no Colégio Pedro II, como estudante, até os primeiros anos de atuação como professor nessa instituição e na Escola Normal. Na segunda parte, foi analisado como a proposta de mudança curricular de Euclides Roxo, inicialmente limitada ao Colégio Pedro II, fundamentada em movimentos internacionais, atingiu a matemática escolar e alterou de maneira significativa elementos que constituem o ensino desta disciplina, como por exemplo, programas de ensino, livros didáticos e a formação do professor.

Nessa primeira parte, Dassie mostrou como Euclides Roxo, um engenheiro por profissão, tornou-se um professor de matemática por ocupação. O autor ressalta que a atuação de engenheiros como professores pode estar articulada às mudanças no mercado de trabalho da época. Com isso Dassie apontou dois possíveis motivos para essa mudança: o primeiro foram as limitações de atuação no campo da engenharia no período de formação de Euclides Roxo; como também a luta dos engenheiros brasileiros contra a concorrência dos estrangeiros, ou seja, a atuação do engenheiro, em torno de 1916, ano que Euclides Roxo se graduou, era limitada.

Como segundo motivo o autor destaca que nas primeiras décadas da República o ensino superior sofreu transformações que modificaram a situação dos diplomados nesse momento, como no caso uma grande expansão do ensino superior, necessitando a contratação de profissionais para ministrarem aulas, assim como postos de gestão em instituições escolares. Esses foram os dois possíveis motivos para Euclides Roxo, um engenheiro por profissão, tornar-se um professor de matemática por ocupação.

Ainda na primeira parte, Bruno Dassie também mostrou a passagem de Euclides Roxo de Professor de Matemática a Educador Matemático. Em seu trabalho, Bruno Dassie evidenciou Euclides Roxo como um intelectual da época, utilizando a concepção de Intelectual sustentada por Sirinelli (2003) o qual considera duas acepções para a noção de intelectual: "uma ampla e sociocultural, englobando os 


\section{Universidade Federal da Grande Dourados}

criadores e os 'mediadores' culturais" e outra "mais estreita e baseada na noção de engajamento na vida da cidade como ator". (Sirinelli, 2003, p. 243, citado por Dassie, 2008, p. 55). Esse aspecto foi a primeira evidência que tornou possível identificarmos uma tentativa de classificar o Professor Euclides Roxo como um Intelectual.

Como o autor não aprofunda esse termo em seu texto, entendemos que Dassie utilizou a concepção de Intelectual proposta por Sirinelli (2003) para sustentar que Euclides Roxo, a partir de suas ideias e atuações ao longo de sua trajetória fez com que ele se tornasse um Educador Matemático. O autor conclui que as experiências como professor e diretor do Colégio Pedro II; membro da comissão de ensino responsável pelos programas; sucesso como autor das Lições de Arithmetica; e sua constante pesquisa em relação aos movimentos internacionais, principalmente a partir das publicações sobre o ensino da matemática em diversos países - bem como sua experiência como professor da Escola Normal, como descrito anteriormente, são suficientes para considerar Euclides Roxo um intelectual, conforme a acepção de Sirinelli. Mas, um intelectual atuante no ensino da matemática, ou seja, um educador matemático (Dassie, 2008, p. 55).

Bruno Dassie (2008) conclui que as ideias de Euclides Roxo alteram significativamente alguns elementos relacionados à matemática escolar, como por exemplo, livros didáticos, abordagem de conteúdos, metodologia de ensino e a formação dos professores. Esses elementos apresentados por Dassie nos possibilitam refletir sobre algumas das características de um Expert em Educação de acordo com os estudos de Hofstetter et al. (2017), entre outros. Assim, esses elementos podem contribuir para outras pesquisas que tenham interesse em analisar os professores que podem ser interpretados, ou não, como Experts em Educação.

O próximo trabalho analisado foi a Dissertação de Mestrado Profissional de Giseli Martins de Souza intitulada "Felix Klein e Euclides Roxo: debates sobre o ensino da matemática no começo do século XX", defendida em 2010. Esse trabalho analisa as propostas do matemático alemão Felix Klein (1849 - 1925) e do professor brasileiro Euclides Roxo (1890 - 1950) para o ensino de matemática, mais especificamente o de geometria, no começo do século XX. 
A pesquisa de Souza (2010) buscou analisar como Euclides Roxo se apropria das ideias de Felix Klein. Essa análise baseia-se na pesquisa das obras desses matemáticos para verificar as relações entre essas publicações feitas em tempos de modernizações do ensino da Matemática, tanto no Brasil quanto na Alemanha. Para tanto, a autora tomou como fonte de pesquisa o livro Matemática Elementar sob um ponto de vista avançado - Geometria, de Felix Klein, e o livro Curso de Mathematica de Euclides Roxo.

Ao abordar essas produções em seu trabalho, Souza (2010) inicialmente analisa as obras de maneira geral, restringindo posteriormente essa análise a um capítulo de cada uma delas. No livro de Felix Klein, a autora restringiu-se à Parte I, limitando o seu estudo ao tratamento dado por Klein às questões relativas ao estudo do comprimento, área e volume. Já no livro de Euclides Roxo, a autora se dedicou a analisar de forma geral o tratamento que Roxo dá a geometria, estabelecendo um elo entre suas ideias e as ideias de Klein.

No capítulo 3, Giseli Souza fez uma "breve" (palavras da autora) biografia de Euclides Roxo e enfatizou o seu papel para a adesão ao Movimento Internacional de Reforma do Ensino da Matemática no Brasil. Para compor a trajetória de vida de Euclides, a pesquisadora utilizou estudos que já haviam abordado o Professor Euclides Roxo em seus trabalhos, como a Tese de Doutorado de Dassie (2008) e a Dissertação de Mestrado de Werneck (2003), ambas já apresentadas anteriormente neste estudo. Além de estudos de outros autores como Maria Ângela Miorim e Wagner Rodrigues Valente, para tratar os reflexos desse movimento no Brasil.

Souza (2010, p. 68) comenta na conclusão do seu trabalho que "as ideias de Roxo estavam inteiramente pautadas nas ideias propostas pelo movimento de reforma internacional e nas ideias de Klein, principalmente no que se refere à adoção de métodos intuitivos e a introdução do conceito de função e do cálculo diferencial e integral". Complementa, ainda, que Euclides Roxo, "baseado nas propostas inovadoras de Klein, buscou conexão entre os três ramos da matemática (Aritmética, Álgebra e Geometria), que inicialmente foi aplicada no currículo de matemática do colégio Pedro II e depois compôs a Reforma Campos". 


\section{Universidade Federal da Grande Dourados}

Quanto ao ensino de Geometria analisado por Souza (2010), a autora ressalta que por mais que Euclides Roxo tenha procurado seguir as ideias de Klein, os dois autores tratam de maneira diferenciada a geometria, "Roxo trabalha com a geometria plana valorizando o método axiomático, enquanto Klein baseia o estudo da geometria nas transformações geométricas e na geometria analítica" (Souza, 2001, p. 68).

O trabalho de Giseli Martins de Souza, abordou o Professor Euclides Roxo a partir da análise de seu Livro Curso de Mathematica 3aㅗ série, enfatizando a parte referente ao ensino da Geometria. No caso do trabalho de Giseli Souza, o ensino de Geometria foi abordado como um conteúdo especifico da matemática para verificar até que ponto o professor Euclides Roxo realmente utilizou as ideias modernizadoras de Felix Klein. Essas ideias inicialmente foram aplicadas no currículo de matemática do colégio Pedro II e depois compôs a Reforma Campos como afirma Souza (2010).

O último trabalho que aborda o Professor Euclides Roxo é a Dissertação de Roberta Botignolo Alves intitulada Os números em sua representação decimal: de Euclides Roxo ao Movimento da Matemática Moderna, defendida em 2014, o qual buscou analisar como o conceito de números racionais veio sendo trabalhado/ apresentado no que hoje é o $6^{0}$ ano/5 $5^{\text {a }}$ série do Ensino Fundamental II, desde a década de 1930, com enfoque principal às ideias do professor Euclides Roxo até o início do Movimento da Matemática Moderna.

Para justificar o seu recorte temporal, Alves (2014) ressalta que escolheu como ponto de partida da sua investigação o ano de 1930, pois foi quando o professor Euclides de Medeiros Guimarães Roxo assumiu o cargo de Diretor do Colégio Pedro II, durante o governo de Getúlio Vargas. Ainda nesse viés Roberta Alves descreve que Roxo foi um dos principais responsáveis pelas modificações sofridas no ensino de Matemática durante as Reformas Educacionais brasileiras, as Reformas Francisco Campos (1931), Gustavo Capanema (1942). Seguindo, o estudo se estende até o início do Movimento da Matemática Moderna (meados da década de 1950).

Para analisar como o conceito de números racionais veio sendo trabalhado/ apresentado Roberta Alves utilizou livros didáticos que abordavam esse conceito. A autora ressalta que a opção por analisar livros didáticos partiu de indagações pessoais 
sobre como eram apresentados tal conceito, desde Euclides Roxo perpassando pelas reformas educacionais brasileiras chegando até o Movimento da Matemática Moderna verificando se existe ou não, alguma interferência das ideias e ideais de Euclides Roxo.

Antes de abordar o livro didático escrito por Euclides Roxo, a autora apresenta, uma breve história da vida desse professor, enfatizando aspectos de sua vida acadêmica. Em uma subseção intitulada "Um pouco da vida acadêmica de Euclides Roxo", Alves (2014) descreve de forma breve as ocupações e algumas publicações de Euclides. Quanto a atuação profissional de Euclides Roxo, a autora ressaltou alguns cargos que ele exerceu no decorrer de sua trajetória no Colégio Pedro II (CPII), tendo sido aluno (1904), professor substituto de Aritmética (1915), catedrático de Matemática (1919) em substituição à Eugênio de Barros Raja Gabaglia, diretor do Externato (1925) e diretor do Internato (1930). Além disso, Roxo também se tornou membro do conselho e diretor da Associação Brasileira de Educação (ABE) em 1929.

De acordo com Alves (2014), Euclides Roxo "por ter atuado como Secretário do Interior do governo do estado de Minas Gerais, onde elaborou reformas entre os anos de 1926 e 1929, foi convidado a incorporar uma comissão para elaborar o programa de Matemática na Reforma Francisco Campos em 1930 [...]" (Alves, 2014, p. 55) Esse fato nos remete mais uma vez a um dos elementos que envolve o conceito de expert no que diz respeito a identificar uma convocatória/mandato por uma autoridade educacional;

A Dissertação de Roberta Alves teve como orientadora a professora Aparecida Rodrigues Silva Duarte, que é autora do primeiro trabalho desenvolvido abordando a trajetória do professor Euclides Roxo. Esse evento ressalta a continuidade da disseminação de pesquisas para esse campo, com o fato de pesquisadores virarem orientadores de outras pesquisas envolvendo a mesma temática.

O trabalho de Roberta Botignolo Alves tem uma abordagem voltada para História das Disciplinas Escolares por analisar como o conceito de números racionais veio sendo trabalhado/ apresentado em livros didáticos, desde a década de 1930 até o início do Movimento da Matemática Moderna. A autora abordou o professor Euclides 


\section{Universidade Federal da Grande Dourados}

Roxo em seu trabalho por meio de seus livros didáticos, mais especificamente o "Curso de Mathematica Elementar", lançado no ano de 1929.

\section{Abordagens, Ações Docentes e Produções ACADÊmicas}

A partir da descrição analítica das produções investigadas, percebemos que os autores procuram narrar e analisar a trajetória de vida e obra do professor Euclides de Medeiros Guimarães Roxo a partir de abordagens e perspectivas diferentes. Nesse viés procuramos sintetizar os modos de abordagens das produções e suas contribuições para as pesquisas sobre Expert em Educação a partir de um quadro síntese ilustrado a seguir:

Quadro 1: Abordagens e contribuições das produções em análise

\begin{tabular}{|c|c|c|c|}
\hline Produção & Autor & Abordagem & $\begin{array}{l}\text { Contribuição para as } \\
\text { pesquisas sobre } \\
\text { Expert em Educação }\end{array}$ \\
\hline $\begin{array}{l}\text { Henri Poincaré e } \\
\text { Euclides Roxo: } \\
\text { Subsídios para a } \\
\text { História das } \\
\text { Relações entre } \\
\text { Filosofia da } \\
\text { Matemática e } \\
\text { Educação } \\
\text { Matemática }\end{array}$ & $\begin{array}{c}\text { Aparecida } \\
\text { Rodrigues } \\
\text { Silva } \\
\text { Duarte }\end{array}$ & $\begin{array}{c}\text { No trabalho da } \\
\text { Aparecida Duarte, } \\
\text { observamos uma } \\
\text { abordagem centrada } \\
\text { nas produções } \\
\text { intelectuais de } \\
\text { Euclides Roxo, mais } \\
\text { especificamente } \\
\text { utilizou uma } \\
\text { abordagem centrada } \\
\text { na análise do } \\
\text { conteúdo dessas } \\
\text { producões. }\end{array}$ & $\begin{array}{l}\text { Situar as referências } \\
\text { produzidas } \\
\text { relativamente ao já } \\
\text { existente. }\end{array}$ \\
\hline $\begin{array}{l}\text { Euclides roxo e a } \\
\text { reforma Francisco } \\
\text { Campos: a gênese } \\
\text { do primeiro } \\
\text { programa de ensino } \\
\text { de Matemática } \\
\text { brasileiro }\end{array}$ & $\begin{array}{c}\text { Arlete } \\
\text { Petry } \\
\text { Terra } \\
\text { Werneck }\end{array}$ & $\begin{array}{c}\text { A autora abordou o } \\
\text { Professor Euclides de } \\
\text { Medeiros Guimarães } \\
\text { Roxo em seu } \\
\text { trabalho pelo viés do } \\
\text { Programa de Ensino } \\
\text { de Matemática de } \\
1931 .\end{array}$ & $\begin{array}{c}\text { Identificar uma } \\
\text { convocatória/mandato. }\end{array}$ \\
\hline
\end{tabular}




\begin{tabular}{|c|c|c|c|}
\hline $\begin{array}{c}\text { Euclides Roxo e a } \\
\text { constituição da } \\
\text { Educação } \\
\text { Matemática no } \\
\text { Brasil }\end{array}$ & $\begin{array}{l}\text { Bruno } \\
\text { Alves } \\
\text { Dassie }\end{array}$ & $\begin{array}{c}\text { O autor abordou o } \\
\text { professor Euclides } \\
\text { Roxo a partir de sua } \\
\text { trajetória } \\
\text { propriamente dita. } \\
\text { Em seu trabalho foi } \\
\text { possível identificar } \\
\text { uma primeira } \\
\text { tentativa de } \\
\text { classificar o } \\
\text { Professor Euclides } \\
\text { Roxo como um } \\
\text { Intelectual. }\end{array}$ & $\begin{array}{l}\text { Seguir as ações dos } \\
\text { experts. }\end{array}$ \\
\hline $\begin{array}{c}\text { Felix Klein e } \\
\text { Euclides Roxo: } \\
\text { debates sobre o } \\
\text { ensino da } \\
\text { matemática no } \\
\text { começo do século } \\
\text { XX }\end{array}$ & $\begin{array}{c}\text { Giseli } \\
\text { Martins } \\
\text { de Souza }\end{array}$ & $\begin{array}{l}\text { O trabalho de Giseli } \\
\text { Martins de Souza, } \\
\text { abordou o Professor } \\
\text { Euclides Roxo a } \\
\text { partir da análise de } \\
\text { seu Livro Curso de } \\
\text { Mathematica } 3^{\text {a }} \text { série, } \\
\text { enfatizando a parte } \\
\text { referente ao ensino } \\
\text { da Geometria. }\end{array}$ & $\begin{array}{l}\text { Produção de novos } \\
\text { saberes por um } \\
\text { personagem. }\end{array}$ \\
\hline $\begin{array}{l}\text { Os números em } \\
\text { sua representação } \\
\text { decimal: de } \\
\text { Euclides Roxo ao } \\
\text { Movimento da } \\
\text { Matemática } \\
\text { Moderna, defendida }\end{array}$ & $\begin{array}{l}\text { Roberta } \\
\text { Botignolo } \\
\text { Alves }\end{array}$ & $\begin{array}{c}\text { A autora abordou o } \\
\text { professor Euclides } \\
\text { Roxo em seu } \\
\text { trabalho por meio de } \\
\text { seus livros didáticos, } \\
\text { mais especificamente } \\
\text { o "Curso de } \\
\text { Mathematica } \\
\text { Elementar", lançado } \\
\text { no ano de 1929. }\end{array}$ & $\begin{array}{l}\text { Identificar uma } \\
\text { convocatória/mandato } \\
\text { por uma autoridade } \\
\text { educacional. }\end{array}$ \\
\hline
\end{tabular}

Fonte: Elaborado pelos autores

Ao longo de suas investigações, os autores Duarte (2002), Werneck (2003), Dassie (2008), Souza (2010) e Alves (2014) discorreram sobre a Trajetória de vida e obra de Euclides Roxo. Nesse sentido, foi possível observar diferentes pontos de vista para verificarmos como os autores tratavam os temas relacionados a Euclides Roxo. Assim, por mais que as produções abordem o mesmo Professor, cada pesquisa encaminhou por um viés, seja pela biografia, pelas análises das obras, pelos decretos, 
programas de ensino ou reformas curriculares os quais Euclides Roxo teve participação.

Vale ressaltar que os termos de Expert e Expertise não estão nas Dissertações e Teses, pois essas produções não tinham esse intuito e nem esses referenciais teóricos. Assim, a partir do referencial teórico-metodológico adotado para este estudo, analisamos essas pesquisas, e a partir dessa análise identificamos elementos que caracterizam essa discussão em torno dos Experts em Educação.

\section{SOBRE SUAS AÇÕES DOCENTES E PRODUÇÕES ACADÊMICAS}

A partir da descrição analítica realizada, sintetizamos as principais ações docentes e produções acadêmicas apresentadas de Euclides Roxo presentes nos trabalhos em análise no decorrer de sua trajetória:

Quadro 2: Síntese de ações docentes e produções acadêmicas de Euclides Roxo

\begin{tabular}{|c|c|}
\hline Formação Acadêmica & $\begin{array}{l}\text { - Formou-se em Engenharia Civil pela } \\
\text { Escola Politécnica do Rio de Janeiro. }\end{array}$ \\
\hline Professor secundário & $\begin{array}{l}\text { - Professor de Aritmética do Colégio Pedro } \\
\text { II. }\end{array}$ \\
\hline Autor de livros e manuais & 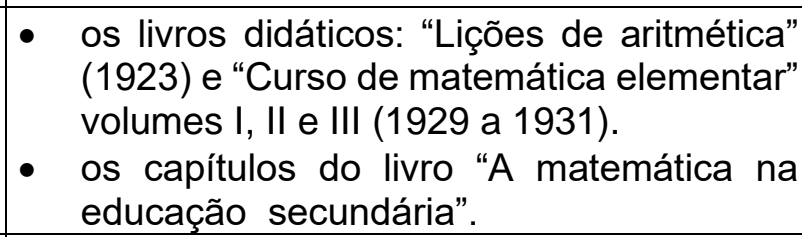 \\
\hline Diretor de escola & $\begin{array}{ll}\text { - } & \text { Diretor do Colégio Pedro II } \\
\text { - } & \text { Diretor do Externato (1925) } \\
\text { - } & \text { Diretor do Internato (1930) }\end{array}$ \\
\hline Publicação de Artigo & $\begin{array}{l}\text { - O artigo "O ensino da matemática na } \\
\text { escola secundária" publicado na revista } \\
\text { SCHOLA em novembro de 1930; } \\
\text { - artigos publicados no "Jornal do } \\
\text { Commercio", no período compreendido } \\
\text { entre novembro de } 1930 \text { a março de } \\
1931 ; \\
\text { - e do artigo "A matemática e o curso } \\
\text { secundário", de cunho especificamente } \\
\text { pedagógico, publicados em } 1937 \text {. }\end{array}$ \\
\hline
\end{tabular}




\begin{tabular}{|c|c|c|}
\hline $\begin{array}{c}\text { Formulação de Programa de } \\
\text { ensino }\end{array}$ & $\begin{array}{l}\text { O programa oficial de ensino de } \\
\text { Matemática de 1931, expresso através do } \\
\text { Decreto } 19.890 \text { de 18/04/1931; }\end{array}$ \\
\hline
\end{tabular}

Fonte: Elaborado pelos autores a partir das informações identificadas nos trabalhos que abordam Euclides Roxo

A partir do quadro das ações docentes e produções acadêmicas de Euclides Roxo, foi possível estabelecer um perfil que aparece da sua trajetória a partir das abordagens feita pelos autores dos trabalhos. Portanto, podemos observar que Euclides Roxo tem um perfil que preenche diferentes ocupações, mais voltado para a docência, autor de livros e Gestão;

No que concerne à formação acadêmica de Euclides Roxo, o qual formou-se em Engenharia Civil pela Escola Politécnica do Rio de Janeiro, mas passou a ser professor de Matemática por atuação. Isso se deu por conta das limitações de exercer a profissão de Engenheiro na época, como ressalta Dassie (2008, p. 222) "num momento em que havia no Brasil escolas de engenharia, mas esta área ainda era um campo limitado para atuação".

Um dos elementos que podemos destacar dentre as ações é o fato de Euclides Roxo ser convidado por Francisco Campos, ministro da Educação e Saúde - Ministério este criado por Getúlio Vargas - para criar os programas de matemática da reforma do ensino brasileiro, a Reforma Campos. Esse elemento é um dos caminhos apontados pelo Projeto Temático para tratar o Conceito de Expert nos projetos de pesquisa, ao qual diz respeito ao primeiro item: 1) Identificar uma convocatória/mandato.

Dessa forma, consideramos as ações docentes e produções acadêmicas apresentadas de Euclides Roxo presentes nos trabalhos em análise no decorrer de sua trajetória como manifestações de sua expertise. Considerando a expertise como um conjunto de saberes necessários que os Experts devem possuir para constituir e exercer suas funções (Hofstetter et al., 2017).

Por fim, pelo quadro apresentado, percebe-se que o professor Euclides Roxo se destacou pelas suas ações docentes e produções acadêmicas que desenvolveram ao longo de sua trajetória. Neste trabalho, não afirmamos que os professores abordados 
nas produções de Teses e Dissertações são Experts em Educação ou não, ao invés disso, apresentamos elementos para outras pesquisas que pretendem tratar sobre esse tema.

\section{CONSIDERAÇÕES FINAIS}

Este artigo buscou delinear os modos como as pesquisas de Mestrado e Doutorado em História da Educação Matemática no Brasil, defendidas entre 1990 e 2018, abordam a trajetória do professor Euclides Roxo, considerando suas ações docentes e produções acadêmicas.

Pelos elementos preenchidos no quadro 3, percebemos que Euclides Roxo foi um profissional atuante no ensino de Matemática e no âmbito escolar. Sua experiência como professor e diretor do Colégio Pedro II; sua participação como membro da comissão de ensino responsável pelos programas; autor de livros e produções acadêmicas; e sua constante pesquisa em relação aos movimentos internacionais, principalmente a partir das publicações sobre o ensino da Matemática em diversos países, bem como sua experiência como professor da Escola Normal, são alguns elementos que os pesquisadores podem levar em consideração a respeito das expertises realizadas por Euclides Roxo.

Ao tratar das ações docentes e produções acadêmicas do professor Euclides Roxo, verifica-se que o mesmo exerceu diversas atividades no decorrer de sua trajetória profissional. Isso nos remete a dizer que o grau de profissionalismo, habilidade e competência de Euclides Roxo fez com que ele se torna-se uma pessoa de destaque dentro da área do ensino de matemática no Brasil, a ponto de ser objeto de investigação científica em um número expressivo de trabalhos como ao que foram por nós analisados.

Assim, dada a importância de se trabalhar com a temática envolvendo professores brasileiros, consideramos esse enfoque relevante por considerar abordar a vida e obra de professores de Matemática que de alguma forma contribuíram para o ensino de Matemática e para a constituição da Educação Matemática brasileira, bem 
como ressaltar as suas contribuições para a área, seja por reformular programas de ensino, elaborar livros e materiais didáticos para o ensino de Matemática. Assim, as reflexões apresentadas por nós se mostram como ponto de partida para a ampliação de um referencial analítico e reflexivo sobre esses estudos com vistas a oferecer elementos para outras pesquisas que pretendem tratar sobre os Experts em Educação.

\section{REFERÊNCIAS}

Bardin, L. (2016) Análise de conteúdo. Tradução Luís Antero Reto; Augusto Pinheiro. 3 reimp. da 1a edição. Lisboa/São Paulo: Edições 70.

Alves, R. B. (2014). Os Números em sua Representação Decimal: de Euclides Roxo ao Movimento da Matemática Moderna [Dissertação de mestrado]. Universidade Anhanguera de São Paulo.

Dassie, B. A. (2008). Euclides Roxo e a Constituição da Educação Matemática no Brasil [Teses doutoral]. Pontifica Universidade Católica do Rio de Janeiro.

Duarte, A. R. S. (2002) Henri Poincaré e Euclides Roxo: Subsídios para a História das Relações entre Filosofia da Matemática e Educação Matemática [Dissertação de Mestrado]. Pontifica Universidade Católica de São Paulo.

Gamboa, S. S. (2012). Pesquisa em educação: métodos e epistemologias.Chapecó: Argos.

Hofstetter, R., Schneuwly, B., y Freymond, M. (2017). "Penetrar na verdade da escola para ter elementos concretos de sua avaliação" - A irreversível institucionalização do expert em educação (século XIX e XX). In: R. Hofstetter 
e W. Valente (Ed.), Saberes em (trans)formação: tema central da formação de professores (1 ${ }^{a}$ ed., p. 55 - 112). São Paulo: Editora Livraria da Física.

Hofstetter, R., e Schneuwly, B. (2017). Saberes: um tema central para as profissões do ensino e da formação. In: R. Hofstetter e W. Valente (Ed.), Saberes em (trans)formação: tema central da formação de professores (1 ${ }^{a}$ ed., p. 113 - 172). São Paulo: Editora Livraria da Física.

Sirinelli, F. (2003). Os intelectuais. In: R. Remond (Ed.). Por uma nova história política. Rio de Janeiro: Fundação Getúlio Vargas.

Souza, G. M. (2010). Felix Klein e Euclides Roxo: debates sobre o ensino da matemática no começo do século XX [Dissertação de mestrado]. Universidade Estadual de Campinas, 2010.

Valente, W. R. (2018). Os experts e a sistematização da matemática para a formação de professores dos primeiros anos escolares, 1890-1990. Projeto de Pesquisa aprovado na FAPESP. UNIFESP.

Werneck, A. P. T. (2003). Euclides Roxo e a Reforma Francisco Campos: A Gênese do Primeiro Programa de Ensino de Matemática Brasileiro [Dissertação de mestrado]. Pontifica Universidade Católica de São Paulo.

\section{CONTRIBUIÇÕES DOS AUTORES}

1a autor: conceitualização; administração do projeto; supervisão; visualização; redação - revisão e edição.

2ำ autor: conceitualização; curadoria de dados; análise formal; investigação; metodologia; redação - rascunho original; redação - revisão e edição. 